\title{
An overview of adult dental fee exemptions in NHS primary dental care in England
}

\author{
Sagar Shah*1 and Valerie Wordley²
}

\section{Key points}

An overview and history of adult dental fee exemptions in NHS primary dental care services.
Assessment of trends in the provision of dental care for fee-exempt adult patients with comparison to adult fee-payers.
Suggestions for the decrease in fee-exempt adult patient attendance over the last ten years with considerations for future oral healthcare planning.

\section{Abstract}

Aims To explore the current landscape of NHS primary dental care services for fee-exempt adult patients and observe attendance, band claiming and geographical patterns.

Materials and methods Data were analysed from FP17 claims submitted to NHS Business Services Authority from 2006-2019.

Results Fee-exempt adult patients in 2018-2019 account for $23.7 \%$ of all adult claims in NHS primary dental care. This percentage has decreased year-on-year since 2011-2012 from 31.5\%. In 2018-2019, there were significantly fewer band 1 claims for fee-exempt adult patients (36.0\%) compared to their fee-paying counterparts (58.3\%). Treatment needs appear to be higher for fee-exempt adult patients since more band 2 and 3 treatment claims were completed (49.0\%) compared to fee-payers (30.8\%). Band 3 claims were three times higher for fee-exempt adult patients.

Discussion Adults with fee exemptions must be able to access timely oral health services since they appear to have higher treatment needs than fee-payers. The areas with the highest proportion of fee-exempt adult patients reflect relative levels of deprivation across regions in England. Barriers to access must be reduced to fully engage all groups of patients and improve oral health.

Conclusion Oral health inequalities appear to exist between fee-paying and fee-exempt adult patients. The postpandemic world will offer a unique opportunity to reassess NHS dental services.

\section{Introduction}

NHS dental care is available to anyone who is ordinarily resident in the United Kingdom. ${ }^{1}$ However, unlike other NHS services, patients requiring dental care can incur a cost for their treatment. Primary dental care services in England are provided by NHS England and NHS Improvement (NHSE\&I) through a general dental service contract or personal dental service contract with NHS dental providers.

${ }^{1}$ Clinical Fellow at NHS Business Services Authority, NHS Dental Services, 1 St Annes Road, Eastbourne, East Susse BN21 3UN, UK; ${ }^{2}$ Clinical Fellow at NHS England and NHS Improvement, Skipton House, 80 London Road, London, SE1 6LH

${ }^{*}$ Correspondence to: Sagar Shah

Email address: sagar.shah2@nhs.net

Refereed Paper.

Accepted 13 July 2020

https://doi.org/10.1038/s41415-021-2790-9
Dental charges were first introduced in 1951, with exemptions protected for those in receipt of income support or who were pregnant or nursing mothers. The decision drew widespread public criticism at the time due to complexities surrounding the new system of payment, which continue to cause problems for patients to this day. Prior to the implementation of the current contract in 2006 in England and Wales, patients could be charged for over 400 different individualised items of treatment. ${ }^{2}$ Although the new banding system has helped to simplify pricing, there still remains some contention around the principle of charging NHS dental patients altogether.

Revenue generated from patient charges has increasingly become an important source of funding for NHS dental services, with the maximum dental charge increasing from $£ 30$ in 1980 to $£ 340$ in $1998 .^{2}$ As of 14 December 2020, there are currently 4 NHS treatment charges:
Band 1 (£23.80), Band 2 (£65.20), Band 3 (£282.80) and Urgent care $(£ 23.80){ }^{3}$ The British Dental Association projects that by 2032 patient contributions will eventually exceed government spending on NHS dental services . ${ }^{4}$

Today, NHS dental exemptions eliminate or reduce treatment costs for adults with low incomes and are available under various government support schemes. ${ }^{5}$ They are also available to those with additional health needs, such as pregnant or nursing mothers. The relationship between socioeconomic status and oral health has been well documented in literature; those with lower status are more likely to have higher unmet oral health needs. ${ }^{6,7}$ Despite this, over three-quarters of adults receive no help with the cost of their treatment. In a survey conducted by the National Association of Citizens Advice Bureaux, 43\% of patients stated that they had avoided a dental check-up in the preceding 12 months because they could not afford the cost. ${ }^{8}$ 


\section{Materials and methods}

\section{Data collection}

Requests for data used in compiling this document were made through Dental Insight (Information Services) at NHS Business Services Authority (NHSBSA) which is a special health authority and an arm's length body of the Department of Health and Social Care. NHSBSA dental services provide activity processing and payment services for NHS dentists in England and Wales. FP17 forms record dental activity and are completed for every course of NHS dental treatment in primary dental care, including community dental and other specialist services.

Data were requested for a breakdown of all adult FP17 claims for fee-exempt and feepaying courses of NHS dental treatment from 2006-2019 in England. A further request was made for total exemptions by type, activity by band for 2014-2019 (fee-exempt versus feepaying) and exemptions by local area team (LAT) for 2018-2019. NHSBSA reports on geographical data in England according to LATs and there are 27 LATs in total.

The data represent total numbers of submitted adult FP17 claims in England and

Fig. 1 FP17 fee-exempt adult claims by exemption type in 2018-2019

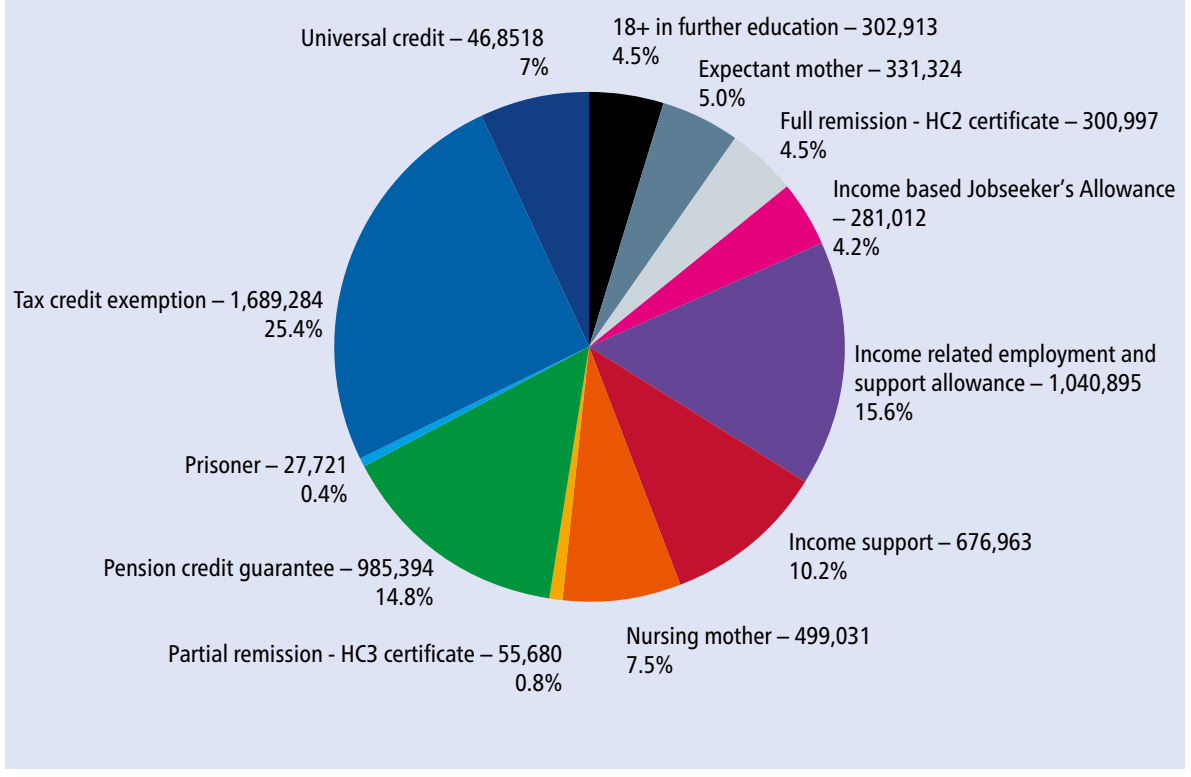

Fig. 2 Total number of FP17 claims submitted for courses of adult dental treatment from 2006-2019

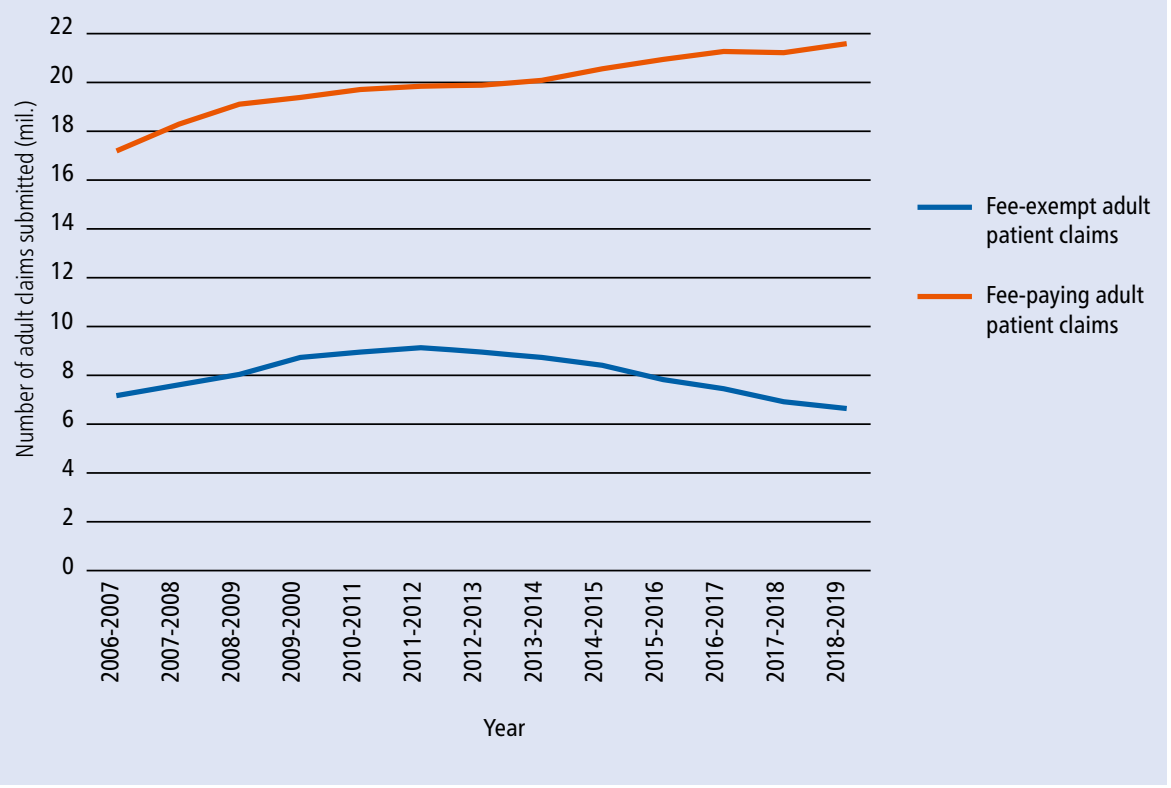

a patient may be counted more than once in a 12-month schedule period where there have been multiple visits. This data do not include private courses of dental treatment.

Financial year 2019-2020 was excluded from this report due to the Coronavirus pandemic, which will have affected data towards the latter part of the year.

\section{Data extraction}

The total form count for all exemption claims was calculated by band to allow comparison with fee-paying patients. The breakdown of fee-exempt adult patients receiving care across each LAT was calculated as a percentage proportion of the total adult dental claims in that region. These percentages were used to identify LATs with the highest proportion of fee-exempt adult claims.

\section{Data limitations}

Eligibility for free or reduced dental care can change. A patient may fall in or out of this category depending on their employment, maternity status, age or other changes in their life (for example, going to prison). Thresholds to qualify for dental exemptions are also changing and not fixed.

\section{Results}

In 2018-2019, 28,150,138 FP17 claims were submitted to NHSBSA for courses of adult dental treatment. Claims attributed to feeexempt adult patients $(6,659,732)$ account for nearly a quarter $(23.7 \%)$ of total adult claims. Figure 1 shows these exemptions by type and volume. The most common entitlement to free dental care was a valid tax credit exemption followed by income-related employment and support allowance. A total of 27,721 FP17 claims were submitted in 2018-2019 for prisoners, which represent the smallest component of all the dental fee exemptions that year.

Figure 2 shows the total number of FP17 claims submitted for fee-paying and fee-exempt adult patients from 2006-2019 in England. Since 2011-2012, there has been a consistent year-on-year decrease in the number of feeexempt courses of treatment submitted - a total reduction of over 2.4 million. Over the same period of time, the numbers of fee-paying claims have increased by over 1.6 million. In 2018-2019, 23.7\% of all adult NHS dental treatment in primary dental care was for feeexempt patients - a reduction from $31.5 \%$ in 2011-2012. 
Table 1 is an outline and comparison of all activity claimed by band for fee-exempt and fee-paying adult patients in 2018-2019. There are significantly fewer band 1 claims for feeexempt adult patients (36.0\%) than fee-paying patients (58.3\%). Treatment needs also appear to be higher in fee-exempt adult patients since more band 2 and 3 treatment claims were completed $(49.0 \%)$ compared to fee payers (30.8\%). Band 3 claims were over three times higher for fee-exempt patients.

Figure 3 demonstrates the percentage proportion of fee-exempt adult FP17 claims by band from 2014-2019. The graph shows that within this 5 -year period the proportion of feeexempt adult claims by band have remained fairly constant, with very little variation.

Table 2 outlines the ten LATs with the highest proportion of fee-exempt adult claims. North East London had the highest proportion at 39\%. For interest, Thames Valley had the lowest proportion at $17.8 \%$. The LATs identified are reflective of relative levels of deprivation across regions in England, where concentrations can be found in cities like Birmingham, Liverpool, Leeds, coastal areas and in parts of East London. ${ }^{9}$ Seven of the most deprived ten districts in England for older people are London boroughs (Tower Hamlets, Hackney, Newham, Islington, Southwark, Lambeth and Haringey), ${ }^{10}$ which correlates with our findings.

\section{Discussion}

The data presented highlight the need for adults with fee exemptions to be able to access timely oral health services. Nearly a quarter of all adult dental claims in primary dental care in England were fee-exempt. This is particularly important since individuals with lower incomes and socioeconomic status experience poorer health outcomes and are more likely to suffer from chronic conditions such as diabetes and cardiovascular disease. ${ }^{11,12,13,14}$ These conditions are known to be associated with oral diseases such as periodontitis. ${ }^{15}$ Patients with lower incomes also experience increased tooth loss in older patient groups. ${ }^{16}$

Adults who qualify for NHS fee exemptions must be able to access regular dental care to maintain their oral health and remain dentally fit. Additionally, if individuals have lower incomes, their children are statistically more likely to suffer from early childhood caries, particularly since high sugar-containing meals
Table 1 A breakdown of activity claimed by band for fee-exempt and fee-paying adult patients in 2018-2019

\begin{tabular}{l|l|l|l|l|l}
\hline Patient & Urgent care & Band 1 & Band 2 & Band 3 & Bands 2 and 3 \\
\hline Fee-exempt adult patients & $14.9 \%$ & $36.0 \%$ & $34.9 \%$ & $14.1 \%$ & $49.0 \%$ \\
\hline Fee-paying adult patients & $10.1 \%$ & $58.3 \%$ & $26.4 \%$ & $4.4 \%$ & $30.8 \%$ \\
\hline
\end{tabular}

\section{Fig. 3 Percentage proportion of fee-exempt adult FP17 claims by band from 2014-2019}

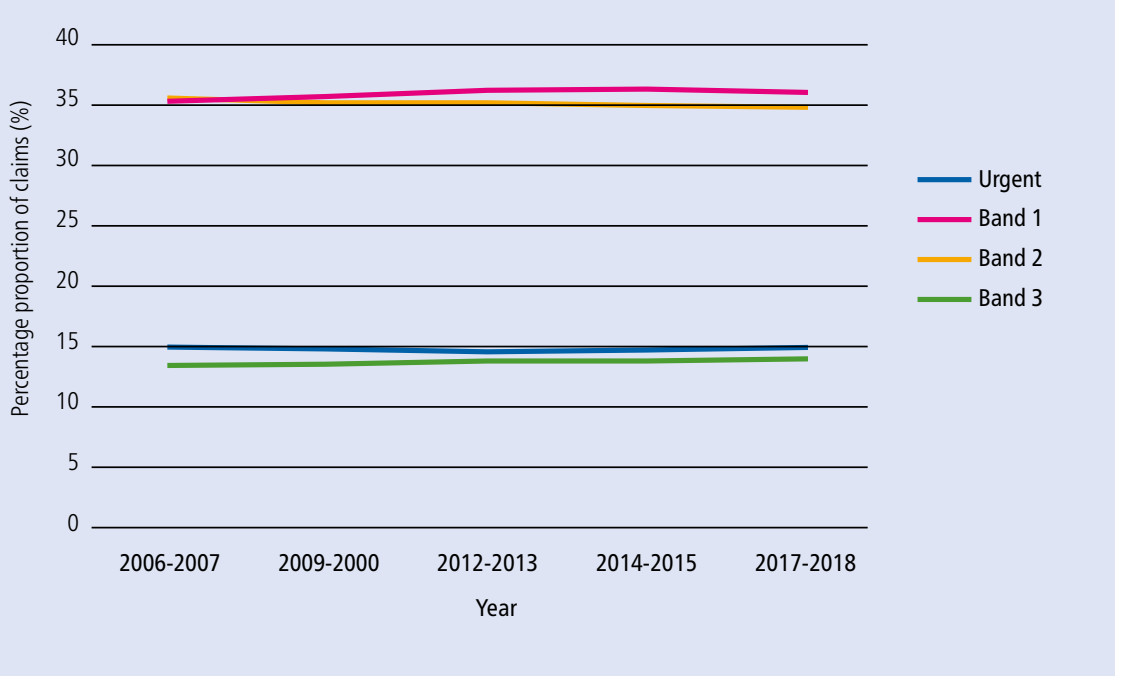

Table 2 Top ten local area teams in England with the highest proportion of claims for fee-exempt adult patients in 2018-2019

\begin{tabular}{l|l} 
Local area teams of England & $\begin{array}{l}\text { Proportion of adult patient claims with fee } \\
\text { exemptions attending the dentist (\%) }\end{array}$ \\
\hline North East London & 39.0 \\
\hline North West London & 36.2 \\
\hline Birmingham and the Black Country & 34.3 \\
\hline South London & 31.6 \\
\hline Merseyside & 30.6 \\
\hline Greater Manchester & 28.7 \\
\hline West Yorkshire & 26.2 \\
\hline Durham, Darlington and Tees & 26.2 \\
\hline Cumbria, Northumberland, Tyne and Wear & 24.6 \\
\hline Lancashire & 24.8 \\
\hline
\end{tabular}

form a cheaper and more readily accessible diet. ${ }^{17}$ Therefore, targeted dental public health programmes in the LATs with the highest proportion of fee-exempt adult claims will help to improve the oral health of both adults and schoolchildren.

\section{Trends in fee-exempt adult attendance patterns}

A noticeable feature of the data is the steady decline in total numbers of fee-exempt adult claims over the last ten years, down by 2.4 million in 2018-2019 from 2011-2012.
For those involved in the delivery of primary dental care services, it is important to understand the possible reasons for this change as significant numbers of patients qualify for free or reduced dental care. It is not within the scope of this paper to suggest reasons for the consistent fall in attendance over the last ten years; however, the following two points can be considered.

Firstly, the unemployment rate has decreased. The unemployment rate dropped from 7.9\% between March-May 2010 to 4\% between December 2019-February 2020. ${ }^{18}$ 
As more people have returned to work, their eligibility for free or reduced dental care may no longer be valid. The major UK welfare system reforms implemented by the government from 2010 also led to changes in eligibility, payments, sanctioning and changes to assessment and entitlement to incapacity and disability-related benefits. ${ }^{19}$

Secondly, an eligibility checking system for NHS fee exemptions was introduced in 2014 to recover funds for the NHS and deter fraud. The system identifies discrepancies (accidental or intentional) between the eligibility status claimed by a patient and the eligibility data stored. A penalty charge notice (PCN) is issued to patients who claim incorrectly, which includes the original cost of their dental treatment and a penalty charge of $£ 100$. Since its introduction, there has been a significant increase in exemption-checking activity. Between 2014-2015 and 2018-2019, data from the National Audit Office found that the money recovered from PCNs for dental treatment rose from $£ 38$ million to $£ 72$ million per year. Over the same five-year period, 200,000 PCNs for dental treatment were subsequently withdrawn because a suitable exemption was confirmed to be in place following challenge. ${ }^{20}$ For patients with a valid fee exemption, this may cause uncertainty and apprehension for future claiming. Conversely, before the eligibility checking system was introduced, some patients may have been claiming inappropriately.

\section{Differences in band claiming for fee-} exempt and fee-paying adult patients

There are key differences in band claiming patterns between fee-exempt and fee-paying adult patients. Fee-exempt adult patients appear to have higher oral health treatment needs and are more likely to require further treatment after their initial band 1 examination. It must be noted that a patient (fee-paying or fee-exempt) can also choose to carry out their treatment privately, even after their initial NHS band 1 examination, which is permissible.

Whether the differences seen in bandclaiming patterns owe to the more challenging care needs of fee-exempt adults or hint at contractual drivers is a fair and honest question. The longitudinal data from 20142019 would suggest that the proportion of claims submitted by band for fee-exempt adult courses has remained almost static. The narrow range of variation in band-claiming patterns would suggest a consistent rhythm and flow of dental activity within this group of patients, although further analysis and study is required. One might expect, over time, a levelling out of care needs between fee-exempt and fee-paying adults; however, the band-claiming incentives in the current NHS dental contract are widely acknowledged. ${ }^{21}$

\section{Improving communications for patient exemptions}

Stakeholders have acknowledged the difficulty patients find in determining their eligibility status. In January 2020, NHSE\&I and NHSBSA began a campaign designed to help patients understand their eligibility for free or reduced NHS dental treatment. This campaign was an extension of the 'check before you tick' exercise initiated in 2018 that was successful in helping patients understand their eligibility for free medical prescriptions. A formal evaluation of outcomes was reported to NHSE\&I and patient behaviour was found to be positively influenced.

A toolkit for dental practices included posters, counter cards and general information directing patients to an online eligibility checker. ${ }^{22}$ Additionally, patients will no longer be issued an immediate charge and will have 28 days to challenge their PCN. The initial letter sent to patients provides an opportunity to confirm their exemption status should there be a discrepancy with the data stored on record. The evaluation and overall outcomes of the dental awareness campaign have yet to be formally reported.

\section{COVID-19 and the future}

More than a year on, the COVID-19 pandemic has had a devastating impact on the UK economy, with GDP falling by $9.9 \%$ in 2020, the largest annual fall in 300 years. ${ }^{23}$ In March 2020, 3 million people were on Universal Credit but the numbers have risen substantially since, reaching 5.8 million people by November $2020 .^{24}$ The Office for Budget Responsibility has also forecast that withdrawal of the Coronavirus Job Retention Scheme and Self-Employment Income Support Scheme will lead to a significant rise in unemployment anticipating a peak at $6.5 \% .^{25}$

With a large increase in adult patients potentially eligible for a dental exemption coupled with increased treatment needs following easing of restrictions (and pressure on providers to meet NHS contract targets), commissioners and dentists must work together to effectively engage and improve access in the long term. The BDA estimates that over 19 million appointments have been delayed since lockdown, ${ }^{26}$ and although dental practices are now open, significant challenges remain in managing the unprecedented backlog in NHS dental care. As with all barriers to access, it is the lowincome disadvantaged patient groups that are most affected and the authors worry that the COVID-19 pandemic will only widen oral health inequalities.

\section{Conclusion}

Adult patients in receipt of exemptions generally have higher oral health needs and may initially require more complex interventions. The long-term challenge is to ensure that patients with fee exemptions continue to seek ongoing care, with reduced access barriers, and that NHS dental services are able to demonstrate improved oral health outcomes. Dentists and commissioning teams must collaborate creatively to reduce the complex oral health gradient that exists between fee-exempt and fee-paying adult patients. The post-pandemic world will offer a unique opportunity to reassess NHS dental services through a new reformed philosophy of care for all patients.

\section{Conflict of interest}

The authors are clinical fellows at NHSBSA and NHSE\&I. Any views expressed are those of the authors and not their seconded organisations.

\section{References}

1. NHS. Using the NHS. 2020. Available at https:// www.nhs.uk/using-the-nhs/nhs-services/visitingor-moving-to-england/moving-to-england-fromthe-european-economic-area-eea-or-switzerland/ (accessed May 2020).

2. House of Commons Health Committee. NHS Charges. 2006. Available at https://publications.parliament. $\mathrm{uk} / \mathrm{pa} / \mathrm{cm} 200506 / \mathrm{cmselect} / \mathrm{cmhealth} / 815 / 815$-i.pdf (accessed May 2020).

3. NHS. Understanding NHS Dental Charges. 2020. Available at www.nhs.uk/using-the-nhs/nhs-services/ dentists/understanding-nhs-dental-charges/ (accessed July 2020)

4. Anonymous. Report: NHS charges are masking cuts and driving patients to GPs. Br Dent J 2016; 221: 286-287.

5. NHS. Who is entitled to free NHS dental treatment in England? 2020. Available at https://www.nhs.uk/ common-health-questions/dental-health/who-isentitled-to-free-nhs-dental-treatment-in-england/ (accessed July 2020).

6. Watt, R, Sheiham A. Inequalities in oral health: a review of the evidence and recommendations for action. Br Dent J 1999; 187: 6-12.

7. Costa S M, Martins C C, Bonfim M L etal. A Systematic Review of Socioeconomic Indicators and Dental Caries in Adults. Int J Environ Res Public Health 2012; 9: 3540-3574.

8. Citizens Advice Bureaux. Charging for health. 2001 Available at https://www.citizensadvice.org.uk/ Global/Migrated_Documents/corporate/unhealthycharges.pdf (accessed May 2020). 
9. House of Commons Library. Deprivation in English constituencies. 2019. Available at https:// commonslibrary.parliament.uk/research-briefings/cbp7327/ (accessed May 2020).

10. English Indices of Deprivation. Ministry of Housing, Communities and Local Government. 2019. Available at https://www.gov.uk/government/statistics/englishindices-of-deprivation-2019 (accessed July 2020).

11. Adler N E, Newman K. Socioeconomic disparities in health: pathways and policies. Health Aff (Millwood) 2002; 21: 60-76.

12. Foraker R E, Rose K M, Chang P P. Socioeconomic status and the trajectory of self-rated health. Age Ageing 2011; 40: 706-711.

13. Saydah S, Lochner K. Socioeconomic status and risk of diabetes-related mortality in the U S. Public Health Rep 2010; 125: 377-388.

14. ClarkA M, DesMeules M, Luo W, Duncan A S, Wielgosz A. Socioeconomic status and cardiovascular disease: risks and implications for care. Nat Rev Cardio/ 2009; 6: 712-722.

15. Liccardo D, Cannavo A, Spagnuolo G et al. Periodontal Disease: A Risk Factor for Diabetes and Cardiovascular Disease. Int J Mol Sci 2019; 20: 1414.
16. Steele J, Shen J, Tsakos G et al. The Interplay between Socioeconomic Inequalities and Clinical Oral Health. J Dent Res 2015; 94: 19-26.

17. Folayan M O, El Tantawi M, Aly N M et al. Association between early childhood caries and poverty in low-and middle-income countries. BMC Oral Health 2020; 20: 8 .

18. Office for National Statistics. Unemployment 2020. Available at https://www.ons.gov.uk/ employmentandlabourmarket/peoplenotinwork/ unemployment (accessed May 2020).

19. Equality and Human Rights Commission. The impact of welfare reform and welfare-to-work programmes: an evidence review. 2018. Available at https://www. niesr.ac.uk/sites/default/files/publications/The $\% 20$ impact $\% 20$ of $\% 20$ welfare $\% 20$ reform $\% 20$ and $\% 20$ welfare-to-work\%20programmes.pdf (accessed July 2020).

20. National Audit Office. Investigation into penalty charges notices in healthcare. 2019. Available at https://www.nao.org.uk/report/investigation-intohealthcare-penalty-charge-notices/ (accessed May 2020).
21. Department of Health. NHS dental services in England: an independent review led by Professor Jimmy Steele. London: Department of Health, 2009.

22. NHS Business Services Authority. NHS help with health costs. 2020. Available at https://www.nhsbsa.nhs.uk/ check-if-youre-eligible-help (accessed May 2020).

23. HM Treasury. Budget 2021: documents - Protecting the jobs and livelihoods of the British people. 2021. Available online at https://www.gov.uk/government/publications/ budget-2021-documents (accessed March 2021).

24. Parliament. Coronavirus: Universal Credit during the crisis. 2021. Available at https://commonslibrary. parliament.uk/research-briefings/cbp-8999/ (accessed March 2021).

25. Office for Budget Responsibility. Economic and fiscal outlook. 2021. Available online at https://obr.uk/efo/ economic-and-fiscal-outlook-march-2021/ (accessed March 2021)

26. BDA. Dentists slam wrongheaded NHS charge hike in middle of pandemic. 2020. Available at https:// bda.org/news-centre/press-releases/dentists-slamwrongheaded-nhs-charge-hike-in-middle-of-pandemic (accessed March 2021) 